Check for updates

Cite this: RSC Adv., 2019, 9, 7301

Received 21st July 2018

Accepted 30th January 2019

DOI: $10.1039 / \mathrm{c} 8 \mathrm{ra0} 6188 \mathrm{~b}$

rsc.li/rsc-advances

\section{Effect of shearing stress on the radial heterogeneity and chromatographic performance of styrene- based polymerised high internal phase emulsions prepared in capillary format $\uparrow$}

\author{
Christopher T. Desire, (D) a R. Dario Arrua, (DD ${ }^{b}$ Fotouh R. Mansour, (D) \\ Stefan A. F. Bon (D) and Emily F. Hilder (D) *b
}

\begin{abstract}
Poly(styrene-co-divinylbenzene) monoliths were prepared from the polymerisation of water-in-monomer high internal phase emulsions consisting of a 90 vol\% internal phase and stabilised by the non-ionic surfactant Span $80 \circledast$. The materials were prepared in capillary housings of various internal diameters ranging from $150 \mu \mathrm{m}$ to $540 \mu \mathrm{m}$ by simply passing the emulsion through the capillaries. When low shear (300 rpm) was used for emulsification, the droplet and resulting void size distributions were observed to shift towards lower values when the emulsions were forced through capillaries of internal diameter less than $540 \mu \mathrm{m}$ and all columns exhibited significant radial heterogeneity. When high shear was employed (14 $000 \mathrm{rpm}$ ) the resulting emulsions preserved their structure when forced through these capillaries and possessed narrower void size distributions with no obvious radial heterogeneity observed upon curing. This resulted in significantly improved chromatographic performance for the separation of a standard mixture of proteins when compared to the materials prepared under low shear.
\end{abstract}

\section{Introduction}

The development of polymer monoliths for chromatography has attracted significant attention since their introduction in the $1990 \mathrm{~s}^{1,2}$ These polymer monoliths are a permanently rigid continuous piece of porous material, ${ }^{2}$ and are typically prepared by a free radical precipitation polymerisation process, using poor solvents for the polymer synthesized. ${ }^{3,4}$ In this approach, the monomers (typically a functional and crosslinking monomer) and the initiator are dissolved in the solvent mixture, which is referred to as the porogen. During the polymerisation process the growing polymer chains undergo phase separation and precipitate as a continuous crosslinked macroporous material with a random globular morphology. ${ }^{5}$

The macroporous nature of these materials is particularly attractive for chromatography as this results in significantly higher column permeabilities when compared to traditional chromatographic formats, such as columns packed with particles where the mobile phase must flow through the smaller

${ }^{a}$ Australian Centre for Research on Separation Science (ACROSS), School of Physical Sciences, University of Tasmania, Hobart, Australia

${ }^{b}$ Future Industries Institute, University of South Australia, Adelaide, Australia. E-mail: Emily.Hilder@unisa.edu.au; Tel: +61883026292

${ }^{c}$ Department of Pharmaceutical Analytical Chemistry, Tanta University, Tanta, Egypt ${ }^{d}$ Department of Chemistry, The University of Warwick, Coventry, CV4 7AL, UK

$\dagger$ Electronic supplementary information (ESI) available. See DOI: 10.1039/c8ra06188b interstitial spaces. ${ }^{6}$ This allows for the use of higher flow rates at the same column back pressure, affording the possibility for rapid separations. In addition, the flow through polymer monoliths is convective in nature, which enhances the mass transport of analytes, in comparison to the diffusion based mass transport of packed columns. ${ }^{7}$ This is particularly important when it comes to the separation of larger molecules, such as proteins, which have low diffusion coefficients. As such, polymer monoliths have been demonstrated to provide excellent separation performance for a variety of larger molecules, including but not limited to: proteins,${ }^{8}$ antibodies, ${ }^{9} \mathrm{DNA}^{10}$ and manmade macromolecules. ${ }^{11}$

While excellent separation performance for these analytes has been demonstrated, one of the limiting factors in applying polymer monoliths for chromatography is the degree of column bed heterogeneity, ${ }^{12,13}$ given their random globular nature. For example, polymer monoliths can exhibit pore size distributions over several orders of magnitude. ${ }^{12}$ In addition, the presence of radial heterogeneity, which is a concern for polymer monoliths, ${ }^{7}$ can significantly reduce their performance as a result of increased band broadening. ${ }^{6}$

Templated approaches have therefore recently been employed for the synthesis of polymer monoliths for chromatography in an effort to improve their homogeneity. ${ }^{14}$ For example, our group previously evaluated the performance of polymer-based cryogels prepared by directional freezing for the separation of proteins by high performance liquid 
chromatography (HPLC). ${ }^{15}$ However, their chromatographic performance was relatively poor when compared to that of conventional monoliths. The polymerisation of high internal phase emulsions (HIPEs) has also emerged as an attractive templating technique for the preparation of polymer monoliths for chromatography. ${ }^{16-21}$

A HIPE is simply an emulsion where the dispersed, and thus internal, phase exceeds $74 \mathrm{vol} \%,{ }^{22}$ which is the characteristic packing density of face centred cubic (fcc) or hexagonally closed packed (hcp) arranged uniform hard spheres. When the continuous phase of a HIPE contains one or more monomeric species, after curing the resulting structure is referred to as a poly(HIPE). When non-ionic surfactants are utilised for stabilisation, poly(HIPE)s with open cellular morphology are typically obtained. These consist of individual cells or voids originating from the emulsion droplets interconnected by pores between voids called windows that allow for transport throughout the structure. Alterations in the structure of the emulsion directly influence the morphology of the resulting material, affording a high degree of control over their structure and the potential to obtain materials with increased homogeneity, in particular with minimal radial heterogeneity. Poly(HIPE)s have therefore been found to be highly suitable for a variety of applications including: as composite materials for combinatorial chemistry, ${ }^{23}$ catalytic supports, ${ }^{24}$ metal chelating agents,${ }^{25}$ tissue engineering scaffolds ${ }^{26}$ and controlled release devices. ${ }^{27}$

However, their application as stationary phases for liquid chromatography (LC) using typical HPLC housing has so far been limited. ${ }^{17,18,20,28-30}$ For example, Yao et al. ${ }^{17}$ prepared poly(glycidyl methacrylate-co-ethylene glycol dimethacrylate) [poly(GMA-co-EGDMA)] poly(HIPE)s in $4.6 \mathrm{~mm}$ internal diameter (i.d.) stainless steel columns for the anion-exchange separation of proteins, while Choudhury et al. ${ }^{20}$ prepared poly(styrene-codivinylbenzene) [poly(Sty-co-DVB)] poly(HIPE)s in $1 \mathrm{~mm}$ i.d. silcosteel tubing for the separation of alkylbenzenes using reversed-phase liquid chromatography (RPLC). Other formats utilised have included thin disks ${ }^{\mathbf{1 6}, 19}$ or membranes, ${ }^{31}$ which ultimately limits the sample capacity. They have also been prepared as flat sheets for thin layer chromatography (TLC). ${ }^{21}$ The chromatographic performance demonstrated so far for poly(HIPE)s has been relatively poor when compared to conventional polymer monoliths, ${ }^{32}$ with most reports demonstrating limited analyte retention. ${ }^{\mathbf{1 6 , 1 7 , 2 8}}$ In addition, relatively few reports have focused in depth on the influence of the pol$y$ (HIPE)s structure on the chromatographic performance. ${ }^{\mathbf{1 6 , 3 0}}$

Of the reports currently available in the literature, only a handful have investigated the preparation of poly(HIPE)s in capillary format, ${ }^{\mathbf{1 8 2 8 , 2 9}}$ which is an extremely attractive format for chromatography due to lower sample and solvent consumption and the reduction of peak broadening as a result of radial diffusion. ${ }^{33}$ For example, Tunç et al. ${ }^{18}$ prepared poly(HIPE)s based on isodecylacrylate and DVB in $100 \mu \mathrm{m}$ i.d. fused silica capillaries for the separation of alkylbenzenes by capillary electrochromatography (CEC), while Choudhury and co-workers reported the separation of alkylbenzenes by CEC using $100 \mu \mathrm{m}$ i.d. capillaries where the capillary wall was coated with a poly(Sty-co-DVB) poly(HIPE).$^{28}$ More recently the same group reported the RPLC separation of alkylbenzenes using graphene oxide modified poly(Sty-co-DVB) poly(HIPE)s prepared in $200 \mu \mathrm{m}$ i.d. capillaries. ${ }^{29}$ These reports only focused on the separation of alkylbenzenes, which are relatively small molecules and are known to be problematic for conventional polymer monoliths. ${ }^{34}$ To the best of our knowledge there exist no examples for the separation of larger molecules, such as proteins, for poly(HIPE)s prepared in capillary format.

In this work we focused on the preparation of poly(Sty-coDVB) poly(HIPE)s in capillaries of various internal diameter and assessed their applicability for the RPLC separation of a common protein mixture. This system was chosen as it has been extensively studied, ${ }^{35}$ and the chromatographic behaviour of conventional poly(Sty-co-DVB) monoliths under RPLC conditions is well documented. ${ }^{36}$ We paid particular attention to the influence of the poly(HIPE)s structure on the chromatographic performance, as well as any alterations in morphology that occurred as a result of their preparation in capillary format. The influence of emulsification energy on the materials structure and chromatographic performance was also studied, with particular attention to the degree of radial heterogeneity present in each case.

\section{Experimental}

\section{Materials}

Acetic acid ( $\geq 99.7 \%$ ), basic alumina (Brockman activity I, 60325 mesh), $\alpha$-chymotrypsinogen A from bovine pancreas, divinylbenzene (DVB, 80\%), lysozyme from chicken egg white $(\geq 90 \%$ ), potassium persulfate (KPS, $\geq 99.0 \%$ ), ribonuclease A, type I-A, from bovine pancreas $(\geq 60 \%)$, sodium hydroxide $(\geq 98.0 \%)$, styrene (Sty, 99\%) and 3-(trimethoxysilyl)propyl methacrylate $(\geq 98 \%)$ were obtained from Sigma-Aldrich (St. Louis, MO, USA). Acetone ( $>98 \%$ ) and ethanol (>99\%) were obtained from Chem-Supply (Gillman, South Australia, Australia). Span® $80(\geq 60 \%)$ and formic acid $(\geq 98.0 \%)$ were obtained from Fluka (Seelze, Hannover, Germany). Acetonitrile ( $\geq 99.8 \%$ ) was obtained from VWR (Radnor, PA, USA). Calcium chloride dihydrate ( $\geq 98.0 \%$ ) was obtained from Ajax Chemicals (Sydney, NSW, Australia). Hydrochloric acid (37\%) was obtained from Merck (Kilsyth, VIC, Australia). Methanol (MeOH, 99.9\%) was obtained from Fisher Scientific (Pittsburgh, Pennsylvania, United States). The monomers (Sty and DVB) were passed through a column of basic alumina to remove inhibitors. KPS was re-crystalized from $\mathrm{H}_{2} \mathrm{O}$. All other chemicals were used as received. The $\mathrm{H}_{2} \mathrm{O}$ used in all experiments was first purified using a Milli-Q system (Millipore). Polyimide-coated capillaries of $150 \mu \mathrm{m}$ i.d. (360 $\mu \mathrm{m}$ o.d.), $250 \mu \mathrm{m}$ i.d. (360 $\mu \mathrm{m}$ o.d.) and 540 $\mu \mathrm{m}$ i.d. (670 $\mu \mathrm{m}$ o.d.) were obtained from Polymicro Technologies.

\section{Modification of fused silica capillaries}

The polyimide-coated capillaries were surface modified based on a procedure by Rohr et al. ${ }^{37}$ Briefly, capillaries were rinsed with acetone and $\mathrm{H}_{2} \mathrm{O}$, activated by pumping a solution of $0.2 \mathrm{M}$ 
sodium hydroxide through the capillaries using a syringe pump at a rate of $30 \mu \mathrm{L} \mathrm{h}^{-1}$ for $30 \mathrm{~min}$. The capillaries were then rinsed with $\mathrm{H}_{2} \mathrm{O}$, before $0.2 \mathrm{M}$ hydrochloric acid was pumped through them at the same rate for $30 \mathrm{~min}$. After which these were rinsed with $\mathrm{H}_{2} \mathrm{O}$ and then ethanol at $\mathrm{pH} 5$ (adjusted using acetic acid). A $20 \mathrm{wt} \%$ solution of 3-(trimethoxysilyl)propyl methacrylate in ethanol at $\mathrm{pH} 5$ was then pumped through the capillaries at $30 \mu \mathrm{L} \mathrm{h}^{-1}$ for $1 \mathrm{~h}$. Finally the capillaries were rinsed with acetone and purged with nitrogen for $2 \mathrm{~min}$ before being left at room temperature for $24 \mathrm{~h}$ to allow for the completion of the condensation reaction.

\section{Preparation of poly(HIPE)s}

Poly(Sty- $c o$-DVB) poly(HIPE)s were prepared from a modified procedure of Hainey et $a l .^{38}$ The internal phase was prepared by dissolving $0.04 \mathrm{~g}$ of KPS and $0.012 \mathrm{~g}$ of calcium chloride dihydrate in $18 \mathrm{~mL}$ of $\mathrm{H}_{2} \mathrm{O}$. This was added dropwise at a rate of 0.3 $\mathrm{mL} \min ^{-1}$ using a Harvard Apparatus Model 33 twin syringe pump to a continuous phase consisting of $0.594 \mathrm{~g}$ of Span ${ }^{\circledR} 80$, $1.6 \mathrm{~mL}$ of Sty and $0.4 \mathrm{~mL}$ of DVB in a $100 \mathrm{~mL}$ round bottom flask with constant stirring at $300 \mathrm{rpm}$. After that, the resulting emulsion was passed through $20 \mathrm{~cm}$ of either 150, 250 and 540 $\mu \mathrm{m}$ i.d. surface-modified fused silica capillaries by hand using a $250 \mu \mathrm{L}$ Hamilton $\circledast$ syringe. The syringe was initially filled with emulsion using a $25 \mathrm{G}$ (5/8 inch) needle. The emulsion emerging from the capillary outlet was collected in $4 \mathrm{~mL}$ glass vials. The capillaries were filled multiple times to limit the number of air bubbles or voids present and the ends were sealed with rubber. This was performed for at least three capillaries for each capillary i.d. These capillaries were placed horizontally in the water bath at $60{ }^{\circ} \mathrm{C}$, as vertical placement has been observed to result in column heterogeneity due to the influence of gravity for conventional polymer monoliths, ${ }^{3}$ and cured for $48 \mathrm{~h}$. The remaining emulsion was transferred to a $25 \mathrm{~mL}$ glass vial as a bulk sample and this was immersed, along with the $4 \mathrm{~mL}$ vials, in the water bath at $60^{\circ} \mathrm{C}$ for $48 \mathrm{~h}$. Once cured the capillaries and vials were removed from the water bath. The bulk material from the vials was removed, cut with the aid of a scalpel into smaller pieces and washed using $\mathrm{MeOH}$ with a Soxhlet apparatus for $24 \mathrm{~h}$, in order to remove the internal phase and any impurities, before being left to dry at $25^{\circ} \mathrm{C}$ in a vacuum oven for 1 week. The capillaries were flushed with $\mathrm{MeOH}$ for $2 \mathrm{~h}$ and then with $\mathrm{H}_{2} \mathrm{O}$ for $2 \mathrm{~h}$ using the capillary LC system at a flow rate of $2 \mu \mathrm{L} \mathrm{min}{ }^{-1}$.

For additional experiments involving the use of longer capillaries or the syringe pump to control the filling rate, the emulsion was prepared as described above. However, for experiments involving increased emulsification energy a modified procedure was adopted, where the internal phase was added dropwise at a rate of 1 drop per second to the continuous phase with constant stirring at $300 \mathrm{rpm}$, after which the emulsion was blended using an IKA Ultra Turrax $\mathrm{T} 25$ homogeniser equipped with an $\mathrm{S} 25 \mathrm{~N} 10 \mathrm{G}$ dispersing element $(7.5 \mathrm{~mm}$ rotor) at $14000 \mathrm{rpm}$ for $2 \mathrm{~min}$. The polymer disks for porosity determination for the different emulsification energies were prepared as described above, except the emulsion was transferred to $10 \mathrm{~mL}$ disposable syringes $(\sim 1.5 \mathrm{~cm}$ in diameter).
These were sealed and placed in the water bath at $60{ }^{\circ} \mathrm{C}$ at an angle of $\sim 45^{\circ}$ from the horizontal to ensure any air bubbles migrated to the top of the syringe and polymerised for $48 \mathrm{~h}$. Once cured these were removed from the syringe, cut into $0.5 \mathrm{~cm}$ thick pieces and then washed with $\mathrm{MeOH}$ using the Soxhlet apparatus for $24 \mathrm{~h}$. These samples were then dried in a vacuum at $25{ }^{\circ} \mathrm{C}$ for 1 week.

\section{Characterisation}

Optical microscopy images of the emulsions immediately after preparation, and when passed through the capillaries, were collected using a Nikon Eclipse E200 microscope equipped with a $10 \times$ objective and a $30.5 \mathrm{~mm} 0.5 \times$ C-mount adapter connected to a 5.0 MP Tucsen IS500 Camera (Fuzhou Xintu Photonics). A few drops of emulsion were placed on a glass slide which had a piece of $500 \mu \mathrm{m}$ thick Teflon covering the perimeter. The Teflon had been adhered using a two-part epoxy adhesive (Araldite 5 Minute Everyday, Shelley Pty. Ltd). An additional glass slide was placed on top to limit evaporation and allow for stable images to be obtained.

Scanning electron micrographs of the poly(HIPE)s obtained were recorded on a Hitachi-SU-70 field emission scanning electron microscope operated in high vacuum mode with an acceleration voltage of $1.5 \mathrm{kV}$. Secondary electrons were detected using a Hitachi scintillator-type detector. The samples were platinum coated (2-3 nm thick coating) using a Bal-Tec SCD 050 Sputter Coater. The average void and window diameters were obtained using Image (NIH Image), where the diameter of at least 300 voids and windows were measured. The values obtained are an underestimation of the true values and it is necessary to introduce a statistical correction ${ }^{39}$ the derivation of which can be found in Barbetta and Cameron, ${ }^{39}$ where the values obtained are multiplied by a factor of $2 /\left(3^{1 / 2}\right)$. The radial distribution of the voids for the capillary cross-sections was also determined by calculating the average diameter of the voids present within the annulus formed from concentric circles, which differed in diameter by $25 \mu \mathrm{m}$ originating from the capillary wall. Capillary cross-sections were obtained using a diamond capillary cutter.

The specific surface area of the poly(HIPE)s was obtained with the Brunauer-Emmett-Teller method ${ }^{40}$ using a Micromeritics Tristar II 2020 automated nitrogen sorption-desorption instrument. Prior to analysis, all samples were dried in a Micromeritics SmartPrep at $70{ }^{\circ} \mathrm{C}$ for $24 \mathrm{~h}$. This was performed using $\sim 100 \mathrm{mg}$ of sample and in triplicate.

The porosity of the bulk samples was estimated by immersing dry polymer disks in $\mathrm{MeOH}$ following a method adapted from Greig and Sherrington. ${ }^{41}$ The mass and dimensions (diameter and height) of these disks were recorded prior to immersion in the solvent. These disks were then placed in centrifuge tubes containing $\mathrm{MeOH}$ for $1 \mathrm{~h}$ before these were centrifuged at $2600 \mathrm{rpm}$ for $15 \mathrm{~min}$. The mass was re-measured and the disks were re-immersed for $5 \mathrm{~min}$ before being centrifuged for an additional $15 \mathrm{~min}$, after which the mass was remeasured. This was repeated until a constant mass was achieved, after which the dimensions of the polymer disks were remeasured. Centrifugation was utilised to ensure the solvent 
entered the pores of the porous polymer. The porosity in the wet state $\left(\varphi_{\mathrm{w}}\right)$ can then be calculated from the following equation:

$$
\varphi_{\mathrm{w}}=\frac{\Delta m / \rho}{V_{\mathrm{w}}}
$$

where $V_{\mathrm{w}}$ is the volume of the swollen polymer disk, $\Delta m$ is the change in mass of the disk and $\rho$ is the density of the solvent, which is $0.792 \mathrm{~g} \mathrm{~mL}^{-1}$ for $\mathrm{MeOH}$ at $25{ }^{\circ} \mathrm{C}$. For both emulsification energies the change in volume was negligible in $\mathrm{MeOH}$, so this provided an estimation of the dry state porosity of the polymer disk.

\section{Chromatography}

Chromatographic separations were performed using a Dionex UltiMate $^{\mathrm{TM}} 3000$ RSLCnano system equipped with a NCS3500RS capillary LC gradient pump including a membrane degasser unit and integrated column compartment, a VWD3400RS UV detector equipped with a $45 \mathrm{~nL}$ flow cell and a WPS-3000TPLC RS autosampler fitted with a $1 \mu \mathrm{L}$ sample loop. Chromeleon ${ }^{\circledR}$ software (Ver. 6.80) was used for system control and data processing (data collection rate was $2.5 \mathrm{~Hz}$ ). Chromatograms were converted to ASCII files and redrawn using Origin ${ }^{\circledR} 8.5$ (OriginLab). The LC experiments were conducted under gradient conditions and $1 \mu \mathrm{L}$ injections were performed with the aid of an autosampler. UV detection was employed at both 214 and $280 \mathrm{~nm}$. For all chromatograms the baseline drift caused by the gradient was subtracted. Comparisons were made to the original chromatograms to ensure that structures observed were not artefacts of the subtraction process. Eluent $\mathrm{A}$ consisted of $0.1 \mathrm{vol} \%$ formic acid in $\mathrm{H}_{2} \mathrm{O}$ and eluent $\mathrm{B}$ consisted of $0.1 \mathrm{vol} \%$ formic acid in acetonitrile and these were degassed prior to use. Samples were dissolved in and diluted with $\mathrm{H}_{2} \mathrm{O}$ to the appropriate concentrations.

Permeability measurements were performed for columns of various lengths by recording the column back pressure at various flow rates between 0.5 and $10 \mu \mathrm{L} \mathrm{min}^{-1}$ in both $\mathrm{MeOH}$ and $\mathrm{H}_{2} \mathrm{O}$ at $25{ }^{\circ} \mathrm{C}$. The pressure was allowed to stabilise for 5 to $10 \mathrm{~min}$ before being recorded. The permeability was then calculated using Darcy's law, ${ }^{33}$ from the slope of a plot of column back pressure against flow rate. The pressure values obtained contained contributions from the back pressure of the system, ${ }^{42}$ to correct for this the slope obtained from a plot of back pressure against flow rate in the absence of the column, over the same range of flow rates, was subtracted from the slope calculated with the column, and this value was used to calculate the permeability. Viscosities of $0.544 \mathrm{mPa}$ s and $0.890 \mathrm{mPa}$ s for $\mathrm{MeOH}$ and $\mathrm{H}_{2} \mathrm{O}$ at $25{ }^{\circ} \mathrm{C}$, respectively, were used in the calculations. ${ }^{43}$ This was performed for at least three columns prepared from the same batch.

\section{Results and discussion}

\section{Preparation of poly(Sty-co-DVB) poly(HIPE)s in capillary format}

Poly(Sty-co-DVB) poly(HIPE)s were first prepared under low shear conditions using an emulsification rate of $300 \mathrm{rpm}$ within surface modified fused silica capillaries of 150, 250 and $540 \mu \mathrm{m}$ i.d. of $20 \mathrm{~cm}$ total length. These capillaries were initially surface modified as this limits the formation of gaps between the monolith and the capillary wall that can result due to shrinkage during polymerisation. ${ }^{44}$ This ensures that the mobile phase flows through the pores of the monolith and not between the monolith and the capillary wall. SEM analysis (Fig. 1) revealed that successful attachment of the monolith to the capillary wall was achieved in all cases. The images in Fig. 1 are taken at different magnifications to show the entire cross-section for each column. Images at the same magnification, showing a smaller section for each column, can be found in Fig. S7.† When $\mathrm{MeOH}$ and $\mathrm{H}_{2} \mathrm{O}$ were pumped through these columns at flow rates between 0.5 and $10 \mu \mathrm{L} \mathrm{min}^{-1}$ the back pressure varied linearly with flow rate (Fig. S1-S3†), indicating no significant compression or mechanical failure of the monolith occurred. ${ }^{44}$ This is important as poly(HIPE)s, in general, are considered to possess poor mechanical properties when exposed to compressive forces, as a result of their low foam density, and this has been limiting for their application in a variety of areas. ${ }^{45,46}$ However, these columns appeared mechanically stable over the range of flow rates utilised.

The back pressure produced by these columns was significantly lower in comparison to that of conventional monoliths, resulting in column permeabilities (Table 1) at least an order of magnitude larger. For example, monoliths prepared through phase separation from a porogen typically possess permeabilities in the range of $(1-10) \times 10^{-14} \mathrm{~m}^{2},{ }^{44,47}$ as compared to the values obtained for these poly(HIPE)s which were in the range of $(1-10) \times 10^{-13} \mathrm{~m}^{2}$. The values calculated when $\mathrm{MeOH}$ was employed as the mobile phase were $(3.5 \pm 0.5) \times 10^{-13},(4 \pm 1)$ $\times 10^{-13}$ and $(1.6 \pm 0.2) \times 10^{-13}$ when prepared in 540, 250 and $150 \mu \mathrm{m}$ i.d. columns, respectively. These values were not statistically different from the values obtained using $\mathrm{H}_{2} \mathrm{O}$ of $(10$ $\pm 6) \times 10^{-13},(5 \pm 2) \times 10^{-13}$ and $(1.7 \pm 0.2) \times 10^{-13}$ for the 540 , 250 and $150 \mu \mathrm{m}$ i.d. columns, respectively. This suggested that no significant swelling or shrinkage occurred in both solvents. These relatively high permeabilities are due to the large windows these materials possess, which were in excess of $1 \mu \mathrm{m}$ (Table 2).

While the permeability values between solvents were not statistically different it can be seen that the values obtained between different internal diameters differed (Table 1), with the permeability appearing to decrease with decreasing capillary i.d. This indicates that although these poly(HIPE)s were prepared from the same emulsion, they possessed different porous properties. ${ }^{47}$ If their porous morphologies were equivalent, each column would have the same back pressure for a given flow velocity, and hence the same permeability ${ }^{44}$ Examining the average void size of the poly(HIPE)s within the capillaries (Table 2) revealed a trend where the average void size appeared to decrease as the capillary i.d. decreased. For example, the average void size went from $20 \pm 10 \mu \mathrm{m}$ to $12 \pm 7$ $\mu \mathrm{m}$ and then to $8 \pm 5 \mu \mathrm{m}$ when the capillary i.d. was decreased from 540 to 250 and then to $150 \mu \mathrm{m}$. While the void size was observed to decrease with decreasing capillary i.d., the void size distribution obtained within the $540 \mu \mathrm{m}$ i.d. column was 


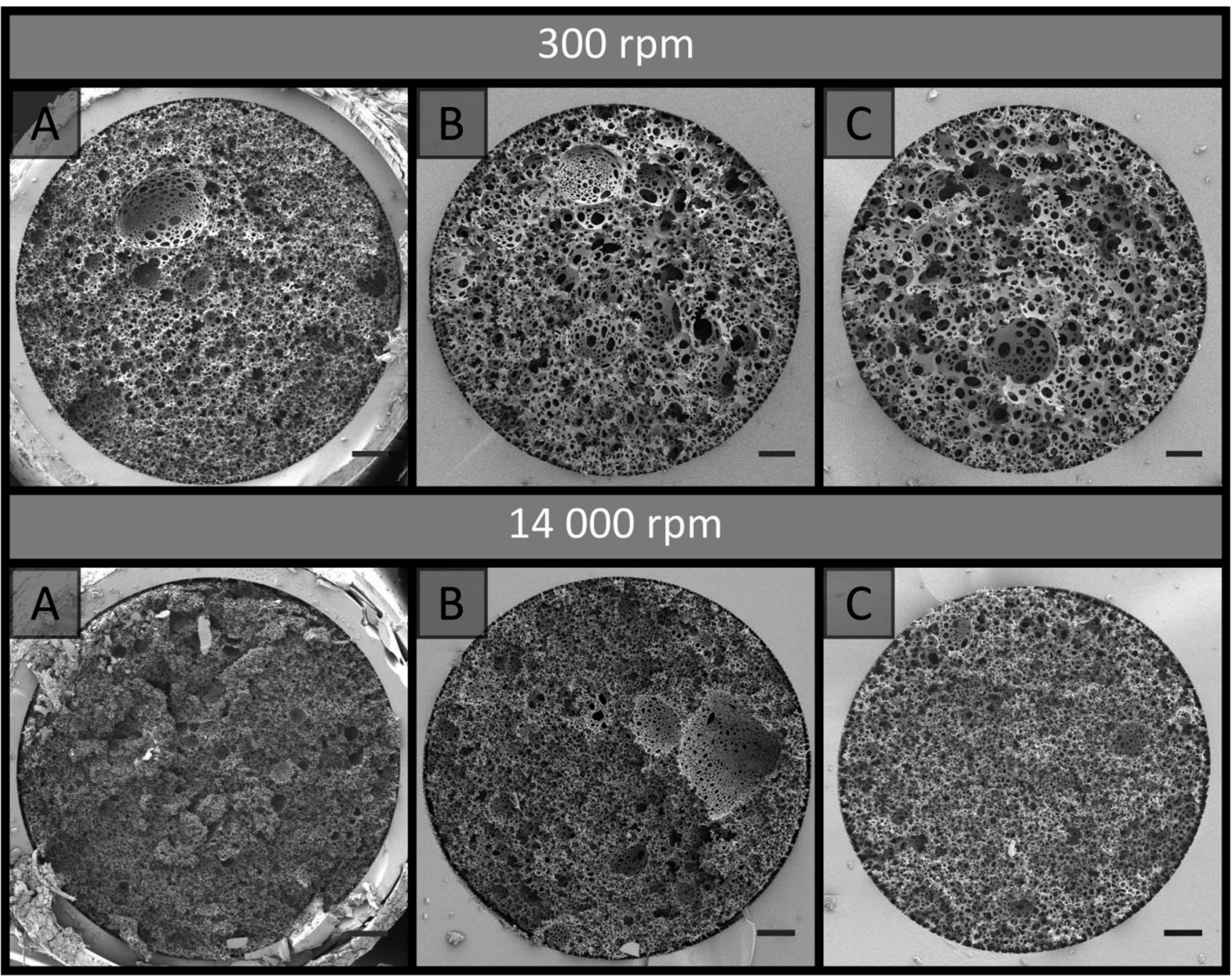

Fig. 1 SEM images of poly(HIPE) capillary stationary phases prepared from high internal phase emulsions made at low shear (300 rpm), without (top series) or with an additional high shear step (14 000 rpm: lower series) and their subsequent polymerization in fused silica capillaries of different internal diameter (i.d.): (A) $540 \mu \mathrm{m}$; (B) $250 \mu \mathrm{m}$; (C) $150 \mu \mathrm{m}$. Scale bars are: (A) $50 \mu \mathrm{m}$; (B) $25 \mu \mathrm{m}$; (C) $15 \mu \mathrm{m}$. Images obtained at the following magnifications: (A) $150 x$; (B) $300 x$; (C) $500 \times$.

identical to that of the bulk material (Table 2), suggesting that the shift in void size only occurred for capillary i.d.s less than $540 \mu \mathrm{m}$. This trend was more apparent for the emulsions that were cured after being passed through $20 \mathrm{~cm}$ of capillary (Fig. 2), with the emulsion passed through the $540 \mu \mathrm{m}$ i.d. capillary resembling that of the bulk material, while a decrease in the void size was visually apparent for the emulsions passed through the 250 and $150 \mu \mathrm{m}$ i.d. capillaries (Table 2). In addition, passing the emulsion through the syringe and/or needle used for filling the capillaries did not appear to reduce the droplet and void size relative to the bulk material (Fig. S8 and S18, Table S1 $\dagger$ ). Decreases in the window size with reduced i.d. were also observed, consistent with the permeability measurements obtained.

The same trend was observed for the emulsion droplets immediately after being passed through the capillaries (Table 2

Table 1 Permeabilities of poly(HIPE)s prepared from emulsions emulsified at 300 or 14000 rpm in capillaries of different i.d. in $\mathrm{MeOH}_{\text {and }} \mathrm{H}_{2} \mathrm{O}$

\begin{tabular}{|c|c|c|c|c|}
\hline 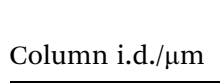 & $\begin{array}{l}\text { Average permeability } \\
(\mathrm{MeOH}) / \times 10^{-13} \mathrm{~m}^{2}\end{array}$ & $\begin{array}{l}\text { Average permeability } \\
\left(\mathrm{H}_{2} \mathrm{O}\right) / \times 10^{-13} \mathrm{~m}^{2}\end{array}$ & $\begin{array}{l}\text { Average permeability } \\
(\mathrm{MeOH}) / \times 10^{-13} \mathrm{~m}^{2}\end{array}$ & $\begin{array}{l}\text { Average permeability } \\
\left(\mathrm{H}_{2} \mathrm{O}\right) / \times 10^{-13} \mathrm{~m}^{2}\end{array}$ \\
\hline 540 & $3.5 \pm 0.5$ & $10 \pm 6$ & $0.3 \pm 0.1$ & $0.3 \pm 0.2$ \\
\hline 250 & $4 \pm 1$ & $5 \pm 2$ & $1.6 \pm 0.5$ & $1.5 \pm 0.3$ \\
\hline 150 & $1.6 \pm 0.2$ & $1.7 \pm 0.2$ & $2.1 \pm 0.5$ & $1.6 \pm 0.2$ \\
\hline
\end{tabular}


Table 2 Porous properties of poly(HIPE)s prepared from emulsions emulsified at 300 or 14000 rpm using capillaries of different i.d.

\begin{tabular}{|c|c|c|c|c|c|c|}
\hline \multirow[b]{2}{*}{ Sample } & \multicolumn{3}{|l|}{$300 \mathrm{rpm}$} & \multicolumn{3}{|c|}{$14000 \mathrm{rpm}$} \\
\hline & $V^{a} / \mu \mathrm{m}$ & $W^{b} / \mu \mathrm{m}$ & $D^{c} / \mu \mathrm{m}$ & $V^{a} / \mu \mathrm{m}$ & $W^{b} / \mu \mathrm{m}$ & $D^{c} / \mu \mathrm{m}$ \\
\hline Bulk & $20 \pm 10$ & $2 \pm 1$ & $7 \pm 4$ & $4 \pm 2$ & $1.4 \pm 0.4$ & $3 \pm 1$ \\
\hline $540 \mu \mathrm{m}$ i.d. & $20 \pm 10$ & $3 \pm 2$ & & $6 \pm 4$ & $1.5 \pm 0.8$ & - \\
\hline $540 \mu \mathrm{m}$ i.d. ${ }^{d}$ & $17 \pm 9$ & $3 \pm 2$ & $7 \pm 5$ & $4 \pm 2$ & $1.2 \pm 0.4$ & $3 \pm 2$ \\
\hline $250 \mu \mathrm{m}$ i.d. & $12 \pm 7$ & $3 \pm 2$ & & $6 \pm 4$ & $1.4 \pm 0.6$ & - \\
\hline $250 \mu \mathrm{m} \mathrm{i.d.} .^{d}$ & $8 \pm 3$ & $2 \pm 1$ & $5 \pm 2$ & $4 \pm 2$ & $1.2 \pm 0.5$ & $3 \pm 1$ \\
\hline $150 \mu \mathrm{m}$ i.d. & $8 \pm 5$ & $2 \pm 1$ & & $4 \pm 3$ & $1.1 \pm 0.4$ & - \\
\hline $150 \mu \mathrm{m}$ i.d. ${ }^{d}$ & $5 \pm 2$ & $1.1 \pm 0.5$ & $4 \pm 2$ & $2.7 \pm 0.8$ & $1.6 \pm 0.6$ & $3 \pm 1$ \\
\hline
\end{tabular}

${ }^{a}$ Average void diameter as determined from SEM. ${ }^{b}$ Average window diameter as determined from SEM. ${ }^{c}$ Average droplet diameter immediately after preparation or after being passed through capillary as determined from optical microscopy. ${ }^{d}$ Indicates emulsion that has been passed through $20 \mathrm{~cm}$ of capillary and cured.

and Fig. S19†). The droplet sizes observed were consistent with the void sizes obtained after curing when passed through the 250 and $150 \mu \mathrm{m}$ i.d. capillaries, suggesting these emulsions were stable during this time. However, the void sizes obtained were significantly larger for the bulk material and the emulsion that was passed through the $540 \mu \mathrm{m}$ i.d. capillary. This indicates that some degree of coalescence occurred for these emulsions, ${ }^{48}$ and suggests that by passing the emulsion through lower i.d. capillaries the stability of the emulsion was enhanced due to the increased droplet packing density. ${ }^{49}$ The porosity of the bulk material was estimated to be $97.1 \pm 0.2 \%$, which is consistent with the $90 \mathrm{vol} \%$ internal phase utilised, but also suggested some degree of creaming may have occurred over time resulting in the slightly higher value ${ }^{22}$ in addition to droplet coalescence. Higher experimental porosities are also sometimes observed due to the removal of surfactant during purification. ${ }^{50} \mathrm{~A}$ decrease in the droplet size often corresponds to increases in the droplet packing and viscosity of the emulsion, which promotes increased stability. ${ }^{22}$ This is consistent with the observation that the emulsion, which initially exhibited a milky consistency, became more viscous after emerging from the 250 and $150 \mu \mathrm{m}$ i.d. capillaries, resembling that of shaving cream, which is more representative of a HIPE. These results suggest that a physical alteration of the emulsion is occurring when it either enters and/or is passed through the capillary when the i.d. is below $540 \mu \mathrm{m}$. Additionally, examination of the void size distributions revealed that when confined within the capillaries the void size distributions obtained were broader, even though their average void sizes were not statistically different from the cured emulsions that had been passed through these capillaries (Table 2). Closer inspection of the capillary cross-sections (Fig. 1) revealed the presence of radial heterogeneity, with small voids towards the outside of the capillaries and larger voids towards the centre. A plot of the average void size measured within the annulus formed from concentric circles, which differed in radius by $25 \mu \mathrm{m}$ originating from the capillary

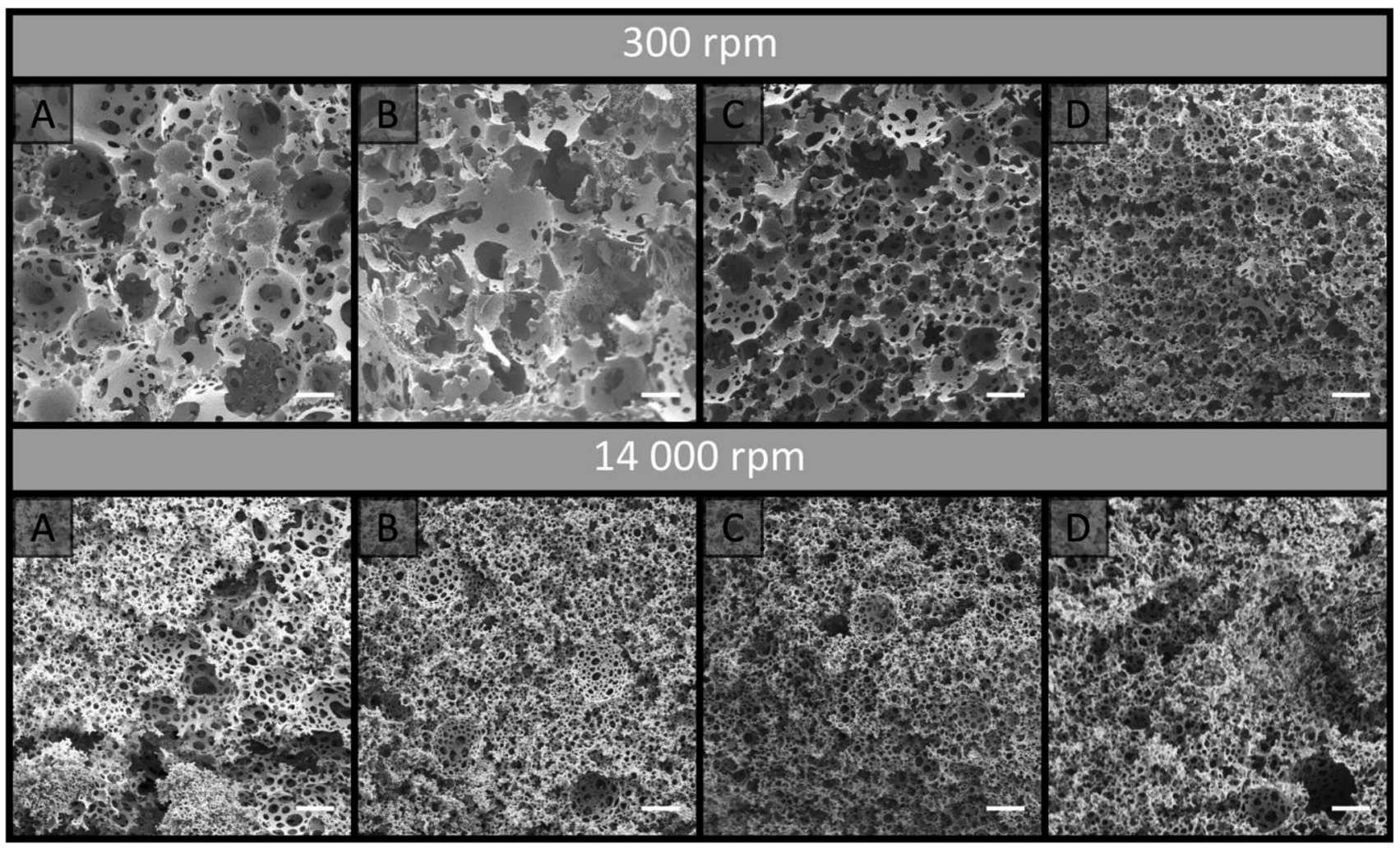

Fig. 2 SEM images of poly(HIPE)s obtained by curing high internal phase emulsions which had been made at low shear (300 rpm), without (top) or with an additional high shear step (14000 rpm: lower series) and subsequently passed through $20 \mathrm{~cm}$ of various i.d. capillaries at the same magnification (obtained at 1000×). (A) Bulk; (B) $540 \mu \mathrm{m}$ i.d.; (C) $250 \mu \mathrm{m}$ i.d.; (D) $150 \mu \mathrm{m}$ i.d. Scale bar is $10 \mu \mathrm{m}$. 
wall, clearly demonstrates this trend (Fig. 3). This increase in average void size did not appear to occur linearly with increased distance from the capillary wall. In comparison, this radial distribution of voids was not obvious for the cured emulsions that had been passed through the respective capillaries (Fig. 2), thus suggesting that the confinement within the capillary is having an additional effect on the resulting material. The presence of radial heterogeneity is particularly concerning from a chromatographic perspective as this can result in deviations from a plug flow profile, resulting in band broadening and compromised chromatographic performance. ${ }^{6}$

Differences in the porous properties for polymer monoliths prepared using a porogen has also been observed when confined within capillaries of different internal diameter. ${ }^{\mathbf{4 4 , 5 1}}$ In these cases the confinement resulted in a non-permeable sheath that forms at the capillary wall during curing, as a result of monomer diffusion, however its presence was only significant for internal diameters less than $50 \mu \mathrm{m}$ where it occupied a significant proportion of the capillary dimensions. No significant wall effect was observed in this work (Fig. 1), and even if present this could not account for the alteration in the emulsions structure itself. A more likely explanation for the shift in porous properties is the shear associated with the emulsion droplets being forced through the narrow capillary inlet and/or traversing along the capillaries length. A higher degree of shear could be expected for narrower capillary i.d.s, thus resulting in increased fragmentation of the emulsion droplets into smaller ones, which is consistent with the results obtained (Table 2), and/or an alteration of the droplet size distribution. If the shift in the emulsions structure occurred gradually along the capillaries length, this would result in longitudinal heterogeneity.
To investigate this, a new batch of columns were prepared in $20 \mathrm{~cm}$ of 540, 250 and $150 \mu \mathrm{m}$ i.d. capillaries and these were cross-sectioned at a variety of lengths between 2 and $18 \mathrm{~cm}$ from the capillary inlet. SEM images of these cross-sections were obtained (Fig. S9-S11 $\dagger$ ). No significant trend was observed for the average void and windows size along the columns length, as these were not statistically different (Table $\mathbf{S} 2 \dagger$ ) for all columns investigated. This suggests that the shift in the emulsions structure occurs at the capillary inlet and not as the emulsion traverses the capillary, and only becomes significant when the capillary i.d. is less than $540 \mu \mathrm{m}$. While a shift in void size along the capillaries length was not observed, these images revealed an additional concern for these materials with the presence of significantly larger voids that appeared randomly throughout the column. The presence of similar voids has also been observed for other poly(HIPE) systems. ${ }^{16,20}$ While coalescence can lead to the presence of larger voids, voids of intermediate size would have also been present if this was the case. ${ }^{50}$ Ostwald ripening, on the other hand, could account for the presence of these larger voids, which were embedded in much smaller ones, ${ }^{52}$ however, given the significant difference in size, their origin is most likely from air bubbles. ${ }^{50}$ These air bubbles, in addition to the radial heterogeneity that was also observed throughout the entire capillary length, will contribute to band broadening.

While the additional shear can account for the shift in droplet and void size observed, this does not explain the presence of radial heterogeneity when the emulsion was confined within the capillaries and cured. A plausible mechanism is capillary hydrodynamic fractionation (CHDF), where, assuming a laminar flow profile, larger droplets are excluded from the slower moving outer regions of the capillary. ${ }^{53}$ This is in principle the same mechanism responsible for the separation of

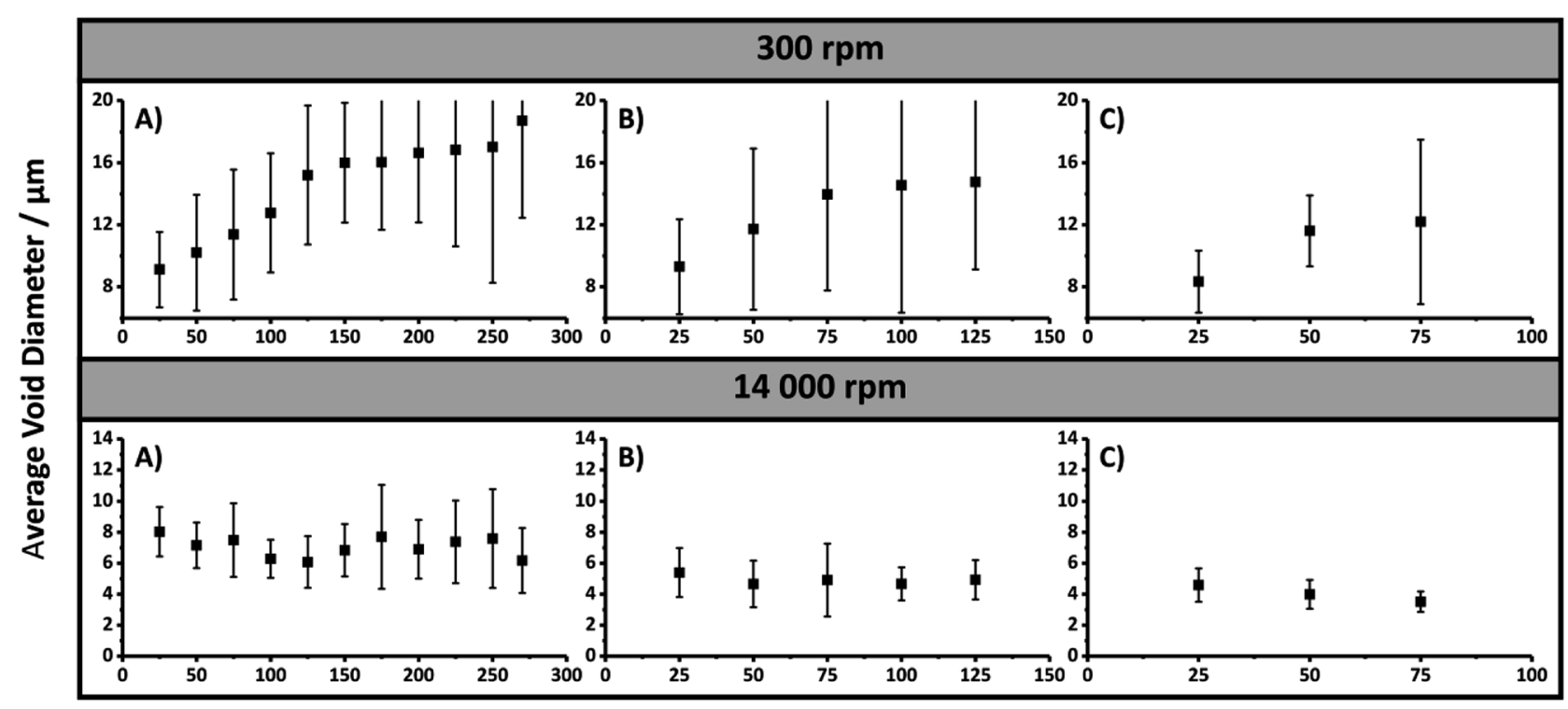

Distance from capillary wall / $\mu \mathrm{m}$

Fig. 3 Plot of average void diameter with increased distance from capillary wall for poly(HIPE)s prepared with emulsification at 300 or $14000 \mathrm{rpm}$ within different capillary i.d.s: (A) $540 \mu \mathrm{m}$; (B) $250 \mu \mathrm{m}$; (C) $150 \mu \mathrm{m}$. 
analytes of different sizes in hydrodynamic chromatography. ${ }^{54}$ Instead of separating the larger droplets from the smaller ones over the length of the column, because the emulsion is being replenished at the inlet, this would result in their concentration towards the centre. This effect is typically only significant for small capillary dimensions, and the same void size distribution would be expected when cured outside the capillary as both the large and small droplets ultimately emerge from the capillary. Another explanation is droplet coalescence as a result of a temperature gradient. Since the polymerisation process is exothermic and heat is easier to dissipate from the outer regions of the column as opposed to the interior, this can result in a thermal gradient across the capillaries diameter. ${ }^{7}$ Since elevated temperatures are known to promote droplet coalescence, ${ }^{22}$ the droplets towards the centre of the column are more likely to undergo a higher degree of coalescence, and a radial temperature gradient would therefore account for the radial distribution of voids observed. This is typically observed for larger column diameters for conventional polymer monoliths, ${ }^{7}$ and is therefore less likely. In addition a similar temperature gradient would be expected for the emulsions cured outside the capillary, which would result in a similar void size distribution. While both CHDF and the presence of a temperature gradient can account for the radial distribution of voids observed, neither provides an explanation for why the void size distribution was narrower when the emulsion was cured outside of the capillary. This could be as a result of the random nature in which these poly(HIPE)s were imaged, as it is difficult to know exactly where a section of the bulk material being imaged was located. Alternatively, the introduction of a small number of air bubbles to the capillary during filling, which become large voids after curing, could account for the broader void size distribution.

Regardless of the mechanism responsible for the radial heterogeneity observed within the capillaries, the influence of passing the emulsion through the capillary inlet, as a result of the additional shear, is clear. While the capillary i.d. has already been shown to influence the resulting droplet diameter, the rate at which the emulsion is forced through the inlet is also expected to influence the emulsions structure, with higher rates corresponding to a greater shear. This was investigated by filling $20 \mathrm{~cm}$ of $250 \mu \mathrm{m}$ and $150 \mu \mathrm{m}$ i.d. capillaries at different rates between 10 and $100 \mu \mathrm{L} \mathrm{min}{ }^{-1}$ using a syringe pump, instead of filling by hand. No significant difference between the droplet and void size distributions (Table S3, Fig. S12, S13, S20 and S21 $\dagger$ ) was observed. However, given the viscous nature of the emulsion emerging from the capillary outlet, this could simply have been a result of the increase in back pressure resulting in difficulties in accurately controlling the flow, particularly if the maximum back pressure of the pump $(99.5$ PSI or 6.86 bar) was exceeded. An alternative method was therefore employed which involved filling the capillaries by hand using different lengths, as increases in capillary length correlate to higher back pressures and therefore lower flow velocities. This was performed for both the 250 and $150 \mu \mathrm{m}$ i.d. capillaries using capillary lengths between 5 and $60 \mathrm{~cm}$. A clear trend was observed with both the droplet and corresponding void size decreasing with decreases in the capillary length for both capillary i.d.s (Table 3, Fig. S14, S15, S22 and S23†). This is consistent with the higher shear associated with higher flow velocities, resulting in increased fragmentation of the droplets as they are forced through the inlet. In all cases the droplet size observed was smaller than the void size obtained after curing suggesting a degree of coalescence occurred.

These results are particularly concerning as the use of low shear mixers for the preparation of poly(HIPE)s for separation science is popular, with most reports utilising shear rates in the order of $300 \mathrm{rpm},{ }^{16-20,29,30}$ as this typically affords larger void and window sizes, allowing high permeabilities to be achieved. However, it is apparent that when these materials are prepared using capillaries with internal diameters less than $540 \mu \mathrm{m}$ significantly different structures are obtained compared to the bulk material, with the capillary i.d. and filling rate having a significant effect. This makes it extremely difficult to predict the behaviour of these materials and in particular control and/ or alter their morphology based on the original emulsification conditions, which is the main advantage of using a templating approach.

In contrast, relatively few reports exist where shear rates in excess of $300 \mathrm{rpm}$ are employed for the preparation of poly(HIPE)s for separation applications, ${ }^{21,55-57}$ of which most utilise shear rates in the order of 1000-3000 rpm using overhead stirrers. ${ }^{21,55,56}$ While the use of high energy mixers with shear rates in excess of $10000 \mathrm{rpm}$ for the preparation of poly(HIPE)s is not uncommon, ${ }^{57}$ their use in this field is extremely limited. ${ }^{57}$ Presumably this is due to the reduced permeability these materials would possess as a result of the smaller voids and windows. ${ }^{45}$

While this is a valid concern, the use of high energy mixers can result in emulsions with increased stability and yield stress, due to the decrease in droplet size and associated increase in droplet packing, ${ }^{45}$ as well as narrower droplet size distributions. $^{50}$ This is potentially beneficial for the preparation in capillary format, as an increase in yield stress reduces the influence of additional shear on the emulsions structure, while the increased stability and/or narrower droplet size distribution may reduce the degree of radial heterogeneity present, depending on the mechanism responsible.

This was investigated by employing a homogeniser and utilising a shear rate of $14000 \mathrm{rpm}$ for emulsification. The emulsion obtained possessed the consistency of shaving cream, in contrast to the milky consistency obtained at the lower shear rate, suggesting this emulsion possessed a higher yield stress. Optical microscopy revealed an average droplet diameter of $3 \pm$ $1 \mu \mathrm{m}$ (Table 2), which was lower but not statistically different to the average droplet diameter of $7 \pm 4 \mu \mathrm{m}$ obtained using a shear rate of $300 \mathrm{rpm}$. However, the droplet size distribution obtained using the higher emulsification energy was narrower. Upon curing an average void diameter of $4 \pm 2 \mu \mathrm{m}$ was obtained, which was not statistically different to the initial droplet size suggesting minimal coalescence occurred, but this was significantly lower than the average void diameter of $20 \pm 10 \mu \mathrm{m}$ obtained using the lower shear rate, highlighting the enhanced stability of this emulsion. The void size distribution was also 
Table 3 Porous properties of poly(HIPE)s prepared from emulsions emulsified at $300 \mathrm{rpm}$ and passed through different lengths of 250 or $150 \mu \mathrm{m}$ i.d. capillaries

\begin{tabular}{|c|c|c|c|c|c|c|}
\hline Length of capillary $/ \mathrm{cm}$ & \multicolumn{3}{|l|}{$250 \mu \mathrm{m}$} & \multicolumn{3}{|l|}{$150 \mu \mathrm{m}$} \\
\hline 10 & $9 \pm 3$ & $2.0 \pm 0.7$ & $4 \pm 2$ & $10 \pm 4$ & $3 \pm 1$ & $4 \pm 2$ \\
\hline 20 & $10 \pm 8$ & $2 \pm 1$ & $5 \pm 2$ & $9 \pm 5$ & $2.3 \pm 0.8$ & $6 \pm 3$ \\
\hline 30 & $10 \pm 5$ & $2.0 \pm 0.7$ & $6 \pm 2$ & $19 \pm 9$ & $4 \pm 2$ & $6 \pm 3$ \\
\hline 60 & $15 \pm 6$ & $3 \pm 2$ & $11 \pm 5$ & $20 \pm 10$ & $5 \pm 2$ & $10 \pm 4$ \\
\hline
\end{tabular}

${ }^{a}$ Average void diameter as determined from SEM. ${ }^{b}$ Average window diameter as determined from SEM. ${ }^{c}$ Average droplet diameter immediately after being passed through capillary as determined from optical microscopy.

narrower. Even though the void size was lower, the average window diameters were not statistically different with a value of $1.4 \pm 0.4 \mu \mathrm{m}$ for emulsification at $14000 \mathrm{rpm}$ and $2 \pm 1 \mu \mathrm{m}$ for emulsification at $300 \mathrm{rpm}$. The porosity of the bulk material was also consistent with that obtained with the lower emulsification energy with a value of $97 \pm 4 \%$, compared to $97.1 \pm 0.2 \%$, suggesting that the use of increased emulsification energy had only altered the void size and void size distribution of the pol$y$ (HIPE) obtained. The specific surface areas were also similar with values of $21.1 \pm 0.8 \mathrm{~m}^{2} \mathrm{~g}^{-1}$ and $25.8 \pm 0.7 \mathrm{~m}^{2} \mathrm{~g}^{-1}$ for emulsification at $14000 \mathrm{rpm}$ and $300 \mathrm{rpm}$, respectively.

When the emulsion was passed through $20 \mathrm{~cm}$ of 540,250 and $150 \mu \mathrm{m}$ i.d. capillary, no alteration in the droplet size (Table 2 and Fig. S24†) or corresponding void and window size (Table 2 and Fig. 2) was apparent, indicating that the emulsion preserved its structure when forced through the capillary inlet as a result of its increased yield stress and insufficient additional shear to further reduce the droplet size. In all cases the void sizes obtained were consistent with the initial droplet size observed by optical microscopy, indicating the emulsions stability was not compromised when it was forced through the capillary. When confined within these capillaries and cured, excellent attachment to the capillary wall was achieved (Fig. 1) and the resulting poly(HIPE)s again possessed similar void and window sizes compared to the bulk material (Table 2). However, the void size distributions were again slightly broader within the capillaries. Examination of the capillary cross-sections revealed the absence of any obvious radial heterogeneity, and no clear trend in the average void size with distance from the capillary wall was observed (Fig. 3).

In terms of column permeabilities (Table 1), the values obtained for both the $250 \mu \mathrm{m}$ and $150 \mu \mathrm{m}$ i.d. columns were not statistically different, with permeabilities of $1.6 \pm 0.5 \times 10^{-13}$ $\mathrm{m}^{2}$ and $2.1 \pm 0.5 \times 10^{-13} \mathrm{~m}^{2}$ in $\mathrm{MeOH}$, consistent with their similar porous properties. These values are not statistically different from the value of $1.6 \pm 0.2 \times 10^{-13} \mathrm{~m}^{2}$ obtained for the poly(HIPE) prepared in the $150 \mu \mathrm{m}$ i.d. capillary using a shear rate of $300 \mathrm{rpm}$. This is not unexpected as these materials shared similar void and window sizes (Table 2). This suggests that the use of the higher emulsification energy resulted in a similar overall structure to that achieved when the emulsion was forced through the $150 \mu \mathrm{m}$ i.d. capillary when emulsified under low shear, albeit with the absence of radial heterogeneity when prepared in capillary format. As such the permeability did not appear to be significantly compromised through the use of a high energy mixer. In contrast, the permeability obtained for the poly(HIPE) prepared in the $540 \mu \mathrm{m}$ i.d. capillary was significantly lower with a value of $0.3 \pm 0.1 \times 10^{-13} \mathrm{~m}^{2}$ using $\mathrm{MeOH}$ as the mobile phase (Table 1), despite it possessing similar void and window sizes (Table 2). The permeability of these materials does not depend solely on average window size, but rather on the smallest window in the flow path. ${ }^{50}$ Therefore, even though these materials shared similar average window sizes, in the case of the poly(HIPE) prepared in the $540 \mu \mathrm{m}$ i.d. capillary it is likely that a small number of smaller windows existed in the flow path resulting in its reduced permeability. For all columns the permeabilities obtained in both $\mathrm{MeOH}$ and $\mathrm{H}_{2} \mathrm{O}$ were similar (Table 1), suggesting limited shrinkage and/or swelling occurred in these solvents, and they appeared mechanically stable with a linear increase in back pressure over the flow rates utilised (Fig. S4-S6†).

The use of increased emulsification energy appears to correspond to emulsions that are capable of preserving their structure when forced through the narrow capillary inlets, unlike the emulsions prepared with low shear. While similar porous properties were obtained to that obtained by passing the emulsion prepared at low shear through the $150 \mu \mathrm{m}$ capillary, the increase in emulsion stability and/or the narrower droplet size distribution appears to have eliminated the presence of radial heterogeneity. Thus these poly(HIPE)s appear to be better candidates as stationary phases for chromatography. However, the use of high energy mixers is not without disadvantages as they are known to introduce air bubbles, which can expand nonuniformly during polymerization resulting in irregular voids. ${ }^{58}$ The presence of these voids can clearly be seen in Fig. 1B, and like those observed in the case of the materials prepared under low shear, these will contribute to band broadening.

\section{Chromatographic performance}

While HPLC is an important technique for the separation of a variety of compounds, it is also a good technique for providing insight into the column bed heterogeneity, as the separation 
resolution is strongly influenced by its Eddy dispersion. ${ }^{15}$ The performance of these poly(HIPE)s for the separation of proteins in liquid chromatography was therefore evaluated by investigating their ability to separate a standard protein mixture consisting of ribonuclease A, lysozyme and $\alpha$-chymotrypsinogen A, under reversed phase conditions. This particular mixture was chosen as the separation of these compounds using poly(styrene)-based monoliths by RPLC is well documented. ${ }^{36}$ The separations obtained for all columns prepared in this work are shown in Fig. 4 using identical gradient conditions and the same flow rate. Higher protein concentrations were utilised for the $540 \mu \mathrm{m}$ i.d. columns to ensure the peaks could adequately be identified from the baseline and provide similar peak intensities, while the same flow rate was utilised to ensure the front of the gradient reached the inlet of the capillary at the same time and that the separation performance was not influenced by the dwell volume of the LC system..$^{33,42}$ Examination of the chromatograms obtained for the poly(HIPE)s prepared using the homogeniser at $14000 \mathrm{rpm}$ revealed a significant improvement in separation resolution of the protein mixture as the capillary i.d. was decreased. Significant co-elution was observed for all proteins for the poly(HIPE) in the $540 \mu \mathrm{m}$ i.d. capillary, while $\alpha$-chymotrypsinogen A was distinguishable from the peak corresponding to both ribonuclease A and lysozyme for the $250 \mu \mathrm{m}$ i.d. capillary. In contrast, all proteins along with the impurity peak corresponding to ribonuclease A and lysozyme were distinguishable when the internal diameter was reduced to
$150 \mu \mathrm{m}$. Decreases in the column i.d. have previously been observed to result in improvements in the chromatographic performance for poly(Sty-co-DVB) monoliths, ${ }^{59}$ however this was as a result of differences in their porous properties as a result of confinement within narrower capillaries. Here, the porous properties of the poly(HIPE)s were similar (Tables 1 and 2) and thus this is the result of a different effect.

The increase in performance is more likely as a result of the decrease in residence time due to the increased flow velocity, given the flow rate utilised for all columns was identical. For example, when a flow rate of $2 \mu \mathrm{L} \mathrm{min}{ }^{-1}$ is utilised the flow velocities for $150 \mu \mathrm{m}, 250 \mu \mathrm{m}$ and $540 \mu \mathrm{m}$ i.d. columns are 1.89 $\times 10^{-3} \mathrm{~m} \mathrm{~s}^{-1}, 0.679 \times 10^{-3} \mathrm{~m} \mathrm{~s}^{-1}$ and $0.146 \times 10^{-3} \mathrm{~m} \mathrm{~s}^{-1}$, respectively. As such, the residence time within the $540 \mu \mathrm{m}$ i.d. capillary is significantly longer than that of the $150 \mu \mathrm{m}$ i.d. capillary, resulting in an increase in band broadening and significant co-elution of the proteins In contrast, an increase in chromatographic performance with decreasing capillary i.d. was not observed in all cases for the poly(HIPE)s prepared using an emulsification rate of $300 \mathrm{rpm}$. While a decrease in capillary i.d. from $540 \mu \mathrm{m}$ to $250 \mu \mathrm{m}$ resulted in a significant improvement in chromatographic performance, with the three proteins becoming distinguishable, significant co-elution between ribonuclease A and lysozyme was observed upon decreasing the capillary i.d. further to $150 \mu \mathrm{m}$. This could suggest that the porous properties of the poly(HIPE) in the $250 \mu \mathrm{m}$ i.d. column was superior to that in the $150 \mu \mathrm{m}$ i.d. column for the

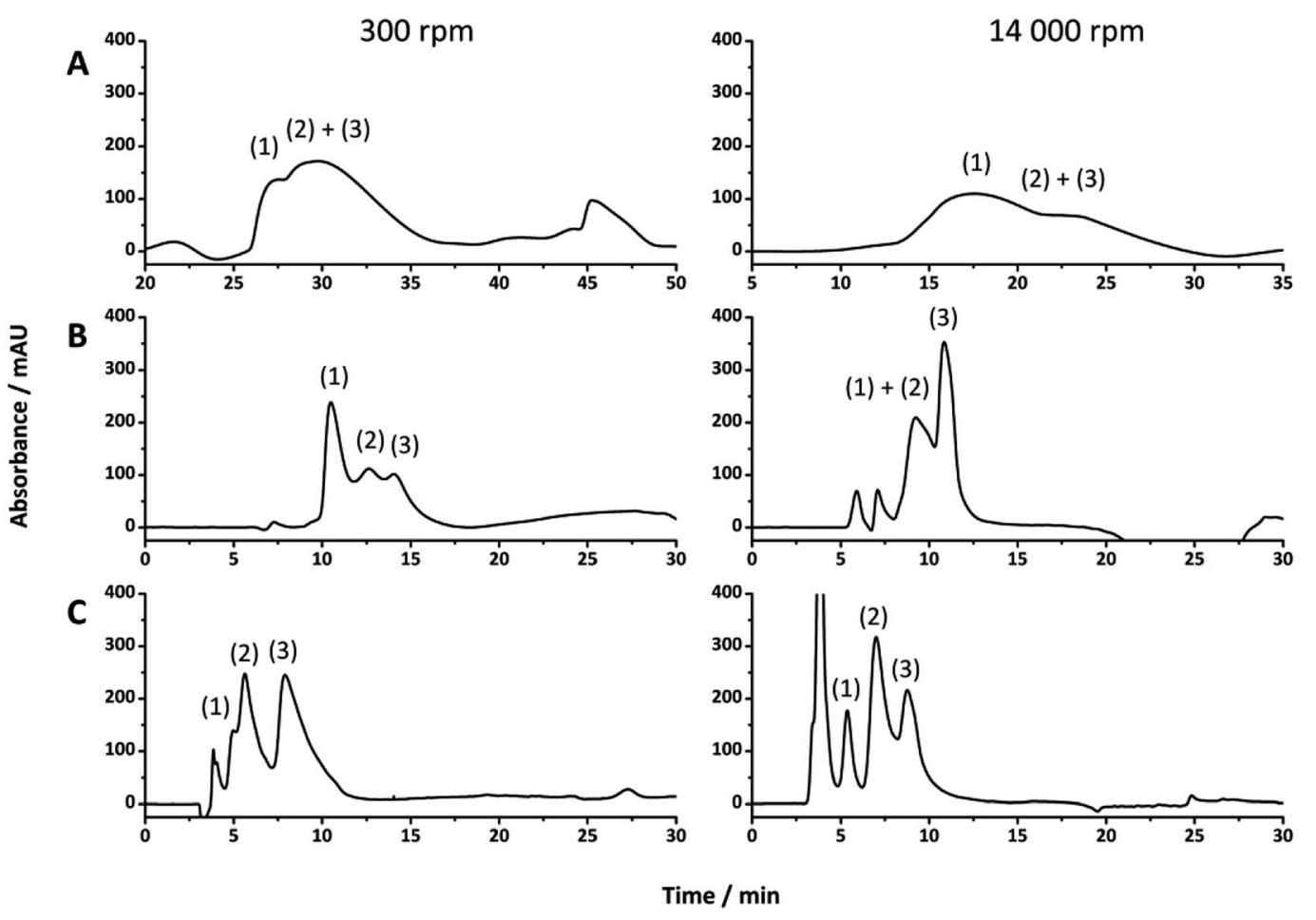

Fig. 4 The separation of ribonuclease A (1), lysozyme (2) and $\alpha$-chymotrypsinogen A (3) under reversed-phase conditions. Conditions: $18 \mathrm{~cm}$ of different i.d. columns: (A) $540 \mu \mathrm{m}$ i.d., (B) $250 \mu \mathrm{m}$ i.d., (C) $150 \mu \mathrm{m}$ i.d., prepared from emulsions using different emulsification energies. Eluent A was 0.1 vol\% formic acid in Milli-Q $\mathrm{H}_{2} \mathrm{O}$, and eluent $\mathrm{B}$ was 0.1 vol\% formic acid in acetonitrile; injection volume, $1 \mu \mathrm{L}$; protein concentration, $0.05 \mathrm{mg} \mathrm{mL}^{-1}$ for (B) and (C) and $0.3 \mathrm{mg} \mathrm{mL}^{-1}$ for (A). Gradient: linear gradient 15 to $90 \% \mathrm{~B}$ in 15 min and then isocratic elution at $90 \% \mathrm{~B}$ for $5 \mathrm{~min}$

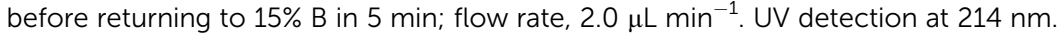


separation of these proteins, however this could simply have been a result of the increase in flow velocity. While comparisons made between columns of different internal diameter at the same flow rate are not reliable, comparisons made between poly(HIPE)s prepared within the same capillary i.d. are more representative. In the case of both the $540 \mu \mathrm{m}$ and $150 \mu \mathrm{m}$ i.d. capillaries the poly(HIPE)s prepared using an emulsification rate of 14000 rpm offered improved chromatographic performance. In contrast, for the separations obtained using the 250 $\mu \mathrm{m}$ i.d. capillaries the performance of the poly(HIPE)s obtained under low shear was superior, as significant co-elution was observed for ribonuclease A and lysozyme for the poly(HIPE)s prepared under high shear. As suggested, this could indicate that the morphology achieved by passing the emulsion prepared under low shear through the $250 \mu \mathrm{m}$ i.d. capillary was better suited for this application, given the similar porous properties obtained for all columns prepared under high shear (Table 2).

In order to achieve a more reliable comparison an additional separation was performed for this column using the same flow velocity as that for the $150 \mu \mathrm{m}$ i.d. columns and the same protein concentration relative to column volume, to ensure a similar column load. ${ }^{44}$ Fig. 5 shows the comparison between this separation and that obtained using the poly(HIPE) prepared under high shear in the $150 \mu \mathrm{m}$ i.d. column. From this it appears that the poly(HIPE) prepared using high shear, in the $150 \mu \mathrm{m}$ i.d. capillary, actually offered significantly improved chromatographic performance and the best separation achieved overall, as the increase in flow velocity and protein loading resulted in significant co-elution between ribonuclease A and lysozyme for the poly(HIPE) prepared under low shear in the 250 $\mu \mathrm{m}$ i.d. column. This co-elution was not as significant as that of

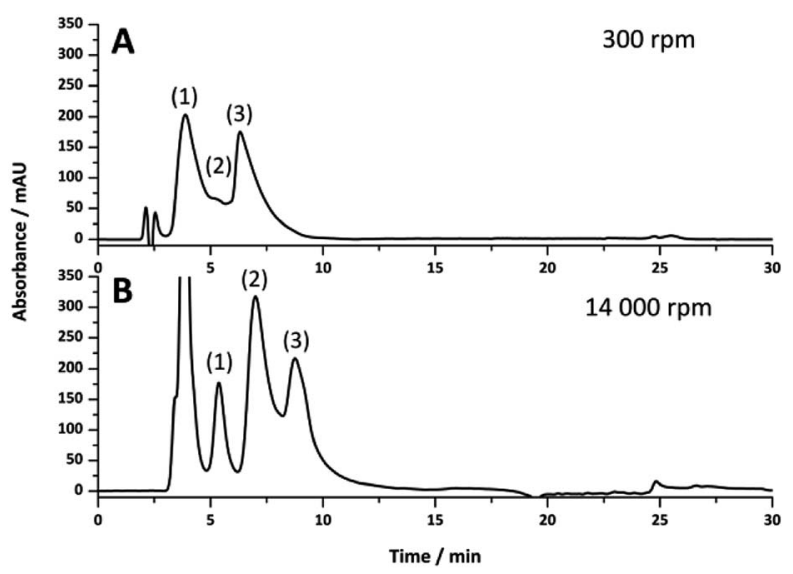

Fig. 5 The separation of ribonuclease A (1), lysozyme (2) and $\alpha$ chymotrypsinogen A (3) under reversed-phase conditions. Conditions: $18 \mathrm{~cm}$ of different i.d. columns: (A) $250 \mu \mathrm{m}$ i.d., (B) $150 \mu \mathrm{m}$ i.d. prepared with different emulsification energies. Eluent $A$ was 0.1 vol\% formic acid in Milli- $Q \mathrm{H}_{2} \mathrm{O}$, and eluent $\mathrm{B}$ was 0.1 vol\% formic acid in acetonitrile; injection volume, $1 \mu \mathrm{L}$; protein concentration, $0.14 \mathrm{mg} \mathrm{mL}^{-1}$ for (A) and $0.05 \mathrm{mg} \mathrm{mL}^{-1}$ for (B). Gradient: linear gradient 15 to $90 \% \mathrm{~B}$ in $15 \mathrm{~min}$ and then isocratic elution at $90 \% \mathrm{~B}$ for 5 min before returning to

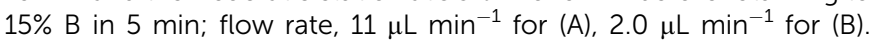
Superficial velocity for both columns was $1.89 \times 10^{-3} \mathrm{~m} \mathrm{~s}^{-1}$. UV detection at $214 \mathrm{~nm}$. the poly(HIPE) prepared under low shear in the $150 \mu \mathrm{m}$ i.d. column (Fig. 4), suggesting that it offered the best separation performance for the poly(HIPE)s obtained using low shear emulsification.

The increase in performance observed for the poly(HIPE)s prepared under high shear is most likely due to the absence of radial heterogeneity and narrower void size distributions, which resulted in a significant reduction in band broadening, as indicated by narrower peaks that appeared more Gaussian in nature. While the poly(HIPE) prepared in the $250 \mu \mathrm{m}$ i.d. column appeared to offer reduced separation performance in comparison to its low shear counterpart, this was likely to have been as a result of increased band broadening associated with the presence of the large irregular voids observed in its structure (Fig. 1B), highlighting an inherent disadvantage associated with their preparation. These larger voids are difficult to eliminate due to the emulsification process and ultimately limit the chromatographic performance of these materials. However, the use of shallower gradients, coupled with an increase in the flow rate, can result in almost baseline resolution for these proteins (Fig. S16 and S17†).

The presence of larger voids has also been observed for other templating techniques used to prepare polymer monoliths for chromatography, resulting in reduced separation performance. ${ }^{15}$ Therefore in order to further improve the chromatographic performance of these materials more focus on the emulsification process itself is required. For example, poly(HIPE)s can be prepared from relatively monodisperse HIPEs obtained using microfluidics, ${ }^{60}$ avoiding the use of a high energy mixer, and this approach may offer a more viable route for the preparation of poly(HIPE)s for chromatography. If the presence of these larger voids can be reduced or eliminated, the chromatographic performance of these materials could approach that of conventional polymer monoliths, where

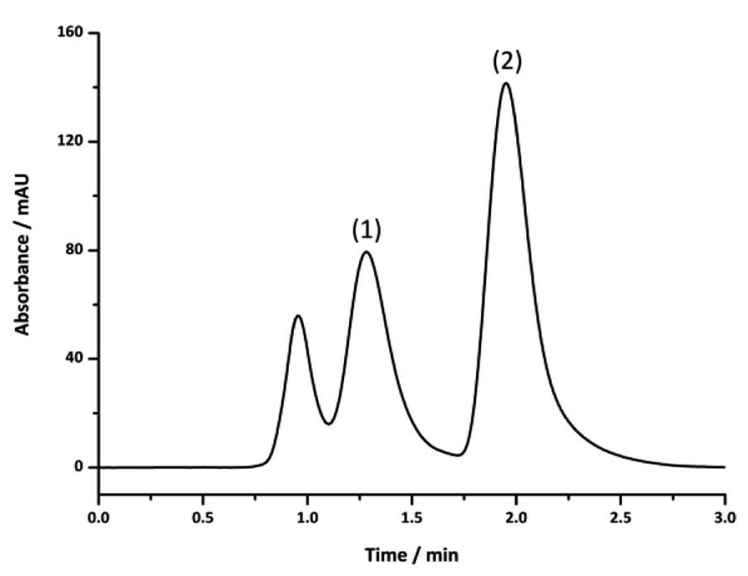

Fig. 6 The separation of ribonuclease A (1) and $\alpha$-chymotrypsinogen A (2) under reversed-phase conditions. Conditions: $18 \mathrm{~cm}$ of $150 \mu \mathrm{m}$ i.d. columns prepared using a shear rate of $14000 \mathrm{rpm}$. Eluent $\mathrm{A}$ was 0.1 vol\% formic acid in Milli-Q $\mathrm{H}_{2} \mathrm{O}$, and eluent $\mathrm{B}$ was 0.1 vol\% formic acid in acetonitrile; injection volume, $1 \mu \mathrm{L}$; protein concentration, $0.05 \mathrm{mg} \mathrm{mL}^{-1}$. Gradient: linear gradient 15 to $50 \% \mathrm{~B}$ in $1.5 \mathrm{~min}$ and then isocratic elution at $90 \% \mathrm{~B}$ for $5 \mathrm{~min}$ before returning to $15 \% \mathrm{~B}$ in $5 \mathrm{~min}$; flow rate, $8.0 \mu \mathrm{L} \mathrm{min}{ }^{-1}$. UV detection at $214 \mathrm{~nm}$. 
baseline resolution of similar protein mixtures is readily achieved. ${ }^{61}$

However, their significantly higher permeabilities may allow for rapid analysis for applications requiring high sample throughput, particularly if the pressure of the LC system is limited, for example miniaturised platforms. For example, this was demonstrated for the separation of ribonuclease A and $\alpha$ chymotrypsinogen (Fig. 6), where baseline resolution was achieved in less than $2.5 \mathrm{~min}$ using a flow rate of $8 \mu \mathrm{L} \mathrm{min}{ }^{-1}$.

\section{Conclusions}

In summary a series of poly(Sty-co-DVB) poly(HIPE)s were prepared in capillary format using high and low shear emulsification. The emulsions prepared under low shear exhibited significant structural change when passed through and confined within capillaries with internal diameters less than $540 \mu \mathrm{m}$ and all columns prepared possessed significant radial heterogeneity. The use of high shear emulsification, on the other hand, resulted in emulsions that preserved their structure when prepared in capillary format, thus reflecting that of the original emulsification conditions. In addition, these materials possessed narrower void size distributions and no significant radial heterogeneity was present. This resulted in significantly improved chromatographic performance for the separation of a standard protein mixture, but their chromatographic performance was ultimately limited by the presence of larger voids, presumably due to the introduction of air bubbles. These materials, however, possessed permeabilities at least an order of magnitude larger than conventional polymer monoliths, which afforded the possibility of achieving rapid separations utilising high flow rates with minimal back pressure.

\section{Conflicts of interest}

There are no conflicts to declare.

\section{Acknowledgements}

This work was supported by the Australian Research Council's Discovery funding scheme (DP130101471). C. T. D. was the recipient of both an Endeavour Fellowship provided by the Australian Government and an Australian Government Research Training Program Scholarship. We gratefully acknowledge Dr Karsten Gömann and Dr Sandrin Feig, from the Central Science Laboratory (CSL), University of Tasmania for their assistance with scanning electron microscopy.

\section{References}

1 S. Hjertén, J.-L. Liao and R. Zhang, J. Chromatogr. A, 1989, 473, 273-275.

2 F. Svec and J. M. J. Fréchet, Anal. Chem., 1992, 64, 820-822. 3 F. Svec and J. M. J. Fréchet, Chem. Mater., 1995, 7, 707-715. 4 C. Viklund, F. Svec and J. M. J. Fréchet, Chem. Mater., 1996, 8, 744-750.
5 C. Viklund, E. Pontén, B. Glad and K. Irgum, Chem. Mater., 1997, 9, 463-471.

6 G. Guiochon, J. Chromatogr. A, 2007, 1168, 101-168.

7 F. Svec and J. M. J. Fréchet, Ind. Eng. Chem. Res., 1999, 38, 3448.

8 F. Svec and J. M. J. Fréchet, J. Chromatogr. A, 1995, 702, 8995.

9 C. T. Desire, R. D. Arrua, M. Talebi, N. A. Lacher and E. F. Hilder, J. Sep. Sci., 2013, 36, 2782-2792.

10 A. Premstaller, H. Oberacher and C. G. Huber, Anal. Chem., 2000, 72, 4386-4393.

11 M. Petro, F. Svec, I. Gitsov and J. M. J. Fréchet, Anal. Chem., 1996, 68, 315-321.

12 H. Koku, R. S. Maier, K. J. Czymmek, M. R. Schure and A. M. Lenhoff, J. Chromatogr. A, 2011, 1218, 3466-3475.

13 T. Mullner, A. Zankel, C. Mayrhofer, H. Reingruber, A. Holtzel, Y. Lv, F. Svec and U. Tallarek, Langmuir, 2012, 28, 16733-16737.

14 S. Choudhury, D. Connolly and B. White, Anal. Methods, 2015, 7, 6967-6982.

15 R. Dario Arrua and E. F. Hilder, $R S C$ Adv., 2015, 5, 7113171138.

16 P. Krajnc, N. Leber, D. Štefanec, S. Kontrec and A. Podgornik, J. Chromatogr. A, 2005, 1065, 69-73.

17 C. Yao, L. Qi, H. Jia, P. Xin, G. Yang and Y. Chen, J. Mater. Chem., 2009, 19, 767-772.

18 Y. Tunç, Ç. Gölgelioğlu, N. Hasirci, K. Ulubayram and A. Tuncel, J. Chromatogr. A, 2010, 1217, 1654-1659.

19 S. Jerenec, M. Šimić, A. Savnik, A. Podgornik, M. Kolar, M. Turnšek and P. Krajnc, React. Funct. Polym., 2014, 78, 32-37.

20 S. Choudhury, L. Fitzhenry, B. White and D. Connolly, Materials, 2016, 9, 212-225.

21 D. Yin, Y. Guan, H. Gu, Y. Jia and Q. zhang, RSC Adv., 2017, 7, 7303-7309.

22 N. R. Cameron and D. C. Sherrington, Adv. Polym. Sci., 1996, 126, 162-214.

23 P. W. Small and D. C. Sherrington, J. Chem. Soc., Chem. Commun., 1989, 1589-1591.

24 E. Ruckenstein and L. Hong, Chem. Mater., 1992, 4, 122-127. 25 S. D. Alexandratos, R. Beauvais, J. R. Duke and B. S. Jorgensen, J. Appl. Polym. Sci., 1998, 68, 1911-1916.

26 A. Barbetta, M. Dentini, M. S. De Vecchis, P. Filippini, G. Formisano and S. Caiazza, Adv. Funct. Mater., 2005, 15, 118-124.

27 H. Zhang and A. I. Cooper, Adv. Mater., 2007, 19, 2439-2444. 28 S. Choudhury, D. Connolly and B. White, J. Appl. Polym. Sci., 2016, 133, 44237.

29 S. Choudhury, E. Duffy, D. Connolly, B. Paull and B. n. White, Separations, 2017, 4, 5.

30 C. Yao, L. Qi, G. Yang and F. Wang, J. Sep. Sci., 2010, 33, 475483.

31 I. Pulko, V. Smrekar, A. Podgornik and P. Krajnc, J. Chromatogr. A, 2011, 1218, 2396-2401.

32 C. T. Desire, E. F. Hilder and R. D. Arrua, Monolithic HighPerformance Liquid Chromatography Columns, Encyclopedia of Analytical Chemistry, 2017, 1-37. 
33 I. Nischang, F. Svec and J. M. Fréchet, J. Chromatogr. A, 2009, 1216, 2355-2361.

34 I. Nischang and T. J. Causon, Trends Anal. Chem., 2016, 75, 108-117.

35 S. D. Kimmins and N. R. Cameron, Adv. Funct. Mater., 2011, 21, 211-225.

36 F. Svec, J. Sep. Sci., 2004, 27, 1419-1430.

37 T. Rohr, E. F. Hilder, J. J. Donovan, F. Svec and J. M. J. Fréchet, Macromolecules, 2003, 36, 1677-1684.

38 P. Hainey, I. M. Huxham, B. Rowatt, D. C. Sherrington and L. Tetley, Macromolecules, 1991, 24, 117-121.

39 A. Barbetta and N. R. Cameron, Macromolecules, 2004, 37, 3188-3201.

40 S. Brunauer, P. H. Emmett and E. Teller, J. Am. Chem. Soc., 1938, 60, 309-319.

41 J. A. Greig and D. C. Sherrington, Polymer, 1978, 19, 163-172.

42 L. Geiser, S. Eeltink, F. Svec and J. M. Fréchet, J. Chromatogr. A, 2007, 1140, 140-146.

43 Y. Li, H. D. Tolley and M. L. Lee, J. Chromatogr. A, 2010, 1217, 4934-4945.

44 I. Nischang, F. Svec and J. M. J. Fréchet, Anal. Chem., 2009, 81, 7390-7396.

45 Y. Luo, A.-N. Wang and X. Gao, Soft Matter, 2012, 8, 75477551.

46 A. Menner, V. Ikem, M. Salgueiro, M. S. P. Shaffer and A. Bismarck, Chem. Commun., 2007, 0, 4274-4276.

47 L. Trojer, S. H. Lubbad, C. P. Bisjak, W. Wieder and G. K. Bonn, J. Chromatogr. A, 2007, 1146, 216-224.
48 S. Kovačič, D. Štefanec and P. Krajnc, Macromolecules, 2007, 40, 8056-8060.

49 C. T. Desire, A. Khodabandeh, T. L. Schiller, R. Wilson, R. D. Arrua, S. A. F. Bon and E. F. Hilder, Eur. Polym. J., 2018, 102, 56-67.

50 M. Tebboth, A. Kogelbauer and A. Bismarck, Chem. Eng. Sci., 2015, 137, 786-795.

51 I. Nischang, O. Brueggemann and F. Svec, Anal. Bioanal. Chem., 2010, 397, 953-960.

52 L. L. Wong, V. O. Ikem, A. Menner and A. Bismarck, Macromol. Rapid Commun., 2011, 32, 1563-1568.

53 C. M. Miller, J. Venkatesan, C. A. Silebi, E. D. Sudol and M. S. El-Aasser, J. Colloid Interface Sci., 1994, 162, 11-18.

54 H. Small, J. Colloid Interface Sci., 1974, 48, 147-161.

55 F. Du, L. Sun, X. Zhen, H. Nie, Y. Zheng, G. Ruan and J. Li, Anal. Bioanal. Chem., 2015, 407, 6071-6079.

56 J. M. Hughes, P. M. Budd, K. Tiede and J. Lewis, J. Appl. Polym. Sci., 2015, 132, 41229.

57 S. Hus, M. Kolar and P. Krajnc, J. Chromatogr. A, 2016, 1437, 168-175.

58 T. H. M. Lau, L. L. C. Wong, K.-Y. Lee and A. Bismarck, Green Chem., 2014, 16, 1931-1940.

59 C. Gu, L. Lin, X. Chen, J. Jia, J. Ren and N. Fang, J. Chromatogr. A, 2007, 1170, 15-22.

60 M. Costantini, C. Colosi, J. Guzowski, A. Barbetta, J. Jaroszewicz, W. Święszkowski, M. Dentini and P. Garstecki, J. Mater. Chem. B, 2014, 2, 2290-2300.

61 Q. C. Wang, F. Svec and J. M. J. Fréchet, Anal. Chem., 1993, 65, 2243-2248. 